\title{
Genetic variation for heterotrophic growth in maize in relation to temperature
}

\author{
C Giauffret *, M Derieux \\ INRA, Laboratoire de Génétique et d'Amélioration des Plantes, 80200 Estrees-Mons, France
}

(Received 12 January 1990; accepted 29 November 1990)

\begin{abstract}
Summary - The investigation was conducted in the frame of early maize (Zea mays L) adaptation to northern Europe climatic conditions. In these countries, tolerance to low temperature during the first stages of development is necessary to ensure a good yield. We were therefore interested in seedling behaviour during heterotrophic growth. We observed rates of radicle elongation of 13 genotypes (inbred lines, hybrids or populations) at 18 controlled temperatures from 6 to $40^{\circ} \mathrm{C}$. One group of genotypes was used to determine endosperm influence. Results of non-linear analysis were in favour of the existence of genetic variation, even if seed effects were not clearly determined. This variation was found to be due to differences in temperature sensitivity or seedling vigour. It was particularly evident for elongation rates (from 0 to $0.2 \mathrm{~mm} / \mathrm{s}$ in a cold environment, and for optimum temperature between 27 and $30^{\circ} \mathrm{C}$ ).
\end{abstract}

maize / temperature / heterotrophic growth / radicle / non linear analysis

Résumé - Variabilité génétique pour la croissance hétérotrophe chez le maïs en relation avec la température. Cette étude se situe dans le cadre de l'adaptation des maïs (Zea mays $L$ ) précoces aux conditions climatiques du Nord de l'Europe. Dans ces régions, la tolérance aux basses températures pendant les premiers stades de développement est nécessaire pour assurer un bon rendement. Nous nous sommes intéressés au comportement de plantules pendant la phase de croissance hétérotrophe. Nous avons observé la vitesse d'élongation de la radicule de 13 génotypes (lignées, hybrides ou populations) à 18 températures comprises entre 6 et $40^{\circ} \mathrm{C}$ (fig 4). Un groupe de génotypes a permis d'étudier l'influence de la qualité de la semence. Les résultats de l'analyse non linéaire permettent de conclure à l'existence d'une variabilité génétique, même si l'effet du support-semence n'a pas pu être précisément défini. Cette variabilité trouve son origine dans des différences de sensibilité aux températures ou dans des différences de niveaux de vigueur. Elle se traduit en particulier par des variations de la vitesse de croissance à basse température entre 0 et $0,2 \mathrm{~mm} / \mathrm{s}$ (tableau III) ou des déplacements de l'optimum thermique entre 27 et $30^{\circ} \mathrm{C}$ (tableau II).

maïs / température / croissance hétérotrophe / radicule / analyse non linéaire

\section{INTRODUCTION}

Numerous studies have investigated the relationships between growth and temperature. Some have shown the existence of genetic variation for maize behaviour related to temperature.

In the frame of early maize adaptation to northern Europe climatic conditions, tolerance to low temperatures during the first stages of development is necessary to ensure a good yield. In these countries, the interception of solar radiation is a limiting factor because the canopy is not fully developed until August, when solar radiation is decreasing (Varlet-Grancher, 1982). Thus it is im- portant to accelerate crop implantation in spring when days are longer. But during this period, temperatures are often too low for a temperaturesensitive species such as maize.

To this end, it would be interesting to find genotypes with an ability to grow at low temperatures during the first stages of development. Some authors (Lehenbauer, 1914; Blacklow, 1972a; Tollenaar et al, 1979) have established response curves of seedling growth to temperature; but they have not investigated a wide genetic variability. Our study consisted of examining radicle elongation in several genotypes (including inbreds and hybrids) as a function of temperature.

\footnotetext{
* Correspondence and reprints.
} 


\section{MATERIALS AND METHODS}

Ten genotypes were studied: 3 populations (Cimmyt Pool 4, Cimmyt Pop 86, INRA population Sexa), 2 single-cross hybrids (F2 x W117, W64A $\times$ F546), and 5 inbred lines (F2, W117, F546, W64A, EP1). They differed in maturity and kernel texture (table I). The single-cross hybrid W117 x F2 was studied in the 2 methods of crossing (W117 and F2 as female parent) and in each case with 2 seed sizes (large size: $>6.5 \mathrm{~mm}$ with F2 as female parent; or $>8 \mathrm{~mm}$ with $\mathrm{W} 117$ as female parent and small size: $\leq 6.5 \mathrm{~mm}$ or $\leq 8 \mathrm{~mm}$ ).

About 30 seeds per genotype were pregerminated at $25^{\circ} \mathrm{C}$ between 2 sheets of blotting paper in Petri dishes. After 2 or 3 days, 12 seedlings with a radicle length of $>10 \mathrm{~mm}$ but $<50 \mathrm{~mm}$ were chosen and transferred to 3 Petri dishes at the desired temperature, each with 2 degrees difference in the range 6 $40^{\circ} \mathrm{C}$. Radicle length was recorded after 8,24 and
$32 \mathrm{~h}$ and elongation rate was then calculated over a 16- and an 8-h period.

We have shown that radicle growth is linear after 10 and up to $50 \mathrm{~mm}$ (Giauffret, 1989). Thus, all the genotypes were compared at the same stage of development during the linear phase of radicle growth. The results for the 2 periods were identical. Only those for the 16-h period are presented here.

The experiment was conducted in the dark in an incubator. To take into account the thermal gradient in the incubator, the Petri dishes were arranged according to a 3-block design.

\section{Statistical analysis}

The temperature response curves for elongation rate were drawn and compared. Comparisons were first made for the linear phase of response. To this end, linear regressions between $14-28{ }^{\circ} \mathrm{C}$ were calculated

Table I. Characteristics of the genotypes studied.

\begin{tabular}{|c|c|c|c|c|}
\hline Genotype & $\begin{array}{l}\text { Genetic } \\
\text { structure }\end{array}$ & Origin & Seed texture & Earliness \\
\hline EP1 & Inbred & $\begin{array}{l}\text { Spain } \\
\text { (Lizargarote } \\
\text { population) }\end{array}$ & Flint & Early \\
\hline $\mathrm{F} 2$ & Inbred & $\begin{array}{l}\text { France } \\
\text { (Lacaune } \\
\text { population) }\end{array}$ & Flint & Early \\
\hline F546 & Inbred & $\begin{array}{l}\text { Françe } \\
(\text { F47 } \times \mathrm{B} 14)\end{array}$ & Flint-dent & Semi-late \\
\hline$W+17$ & Inbred & $\begin{array}{l}\text { Wisconsin, USA } \\
\text { (643 x Pop Min 13) }\end{array}$ & Dent & Semi-early \\
\hline W64A & Inbred & $\begin{array}{l}\text { Wisconsin, USA } \\
\text { (WF9 } \times 187.2 \text { ) }\end{array}$ & Dent & Late \\
\hline $\mathrm{F} 2 \times \mathrm{W} 117$ & Single cross & & Flint & Early \\
\hline $\mathrm{W} 117 \times \mathrm{F} 2$ & Single cross & & Dent & Early \\
\hline W64A x F546 & Single cross & & Dent & Semi-late \\
\hline Pop 86 & Population & $\begin{array}{l}\text { CIMMYT } \\
\text { highlands }\end{array}$ & Mixture & Late \\
\hline Sexa & Population & $\begin{array}{l}\text { France } \\
\text { Péronne }\end{array}$ & Dent & Early \\
\hline Pool 4 & Population & $\begin{array}{l}\text { CIMMYT } \\
\text { highlands }\end{array}$ & Semi-flint & $\begin{array}{l}\text { Late } \\
\text { modified } \\
\text { for earliness }\end{array}$ \\
\hline
\end{tabular}


and the parameters compared between genotypes using a Student test. Analysis was then conducted with a non-linear fitting method.

The maximum of likelihood estimator was chosen in order to perform the likelihood ratio test. This test is based on the comparison of the likelihood of a particular model (estimation of parameters under constraint) to the likelihood of a general model (without constraint). It allows the comparison to be made of fitted curves and estimated parameter. CS-NL procedures (Bouvier et al, 1985) were used to solve the $a, b, c, d$, coefficients in the following model:

$$
Y_{i j}=f\left(t_{i}\right)+E_{i j}=d+a e^{-c t} t_{i} b c+E_{i j}
$$

$y_{i j}$ : elongation rate value for the ith temperature and $j$ th repetition; $t_{i}$ : th temperature; and $E_{i j}$ : error.

Figure 1 shows an example of fitted curve. This gamma model was chosen from the commonly used models with an optimum and which are defined on an infinite interval because of the biological interest of its coefficients. It was slightly modified in order to introduce an additional parameter (d) with a biological significance.

Thus the parameters are: $a$, a scale parameter; $b$, the value of temperature for which the maximum rate occurs:

Radicle elongation rate $(m m \cdot h-1)$

$$
y_{\max }=f(b)
$$

$c$, no determined significance; $d$, the estimate of elongation rate at $0^{\circ} \mathrm{C}: d=f\left(t_{i}\right)$ when $t_{i}=0$.

Fittings are realized according to Gauss-Marquardt algorithm (Lebreton and Millier, 1982).

The comparisons were made in order to determine 3 points:

- does a genetic variation exist for radicle growth between inbred lines, hybrids and populations?

- what is the relation between hybrid and parental inbreds?

- is there an influence of the methods of crossing on kernel size?

\section{RESULTS AND DISCUSSION}

In accordance with the observations of Blacklow (1972a), Crawford and Huxter (1977); McAdam and Hayes (1978), Clarkson and Gerloff (1979), the response curves of radicle elongation rate to temperature are curvilinear with an optimum at $\approx$ $30^{\circ} \mathrm{C}$ and a linear phase between $10-14^{\circ} \mathrm{C}$ and

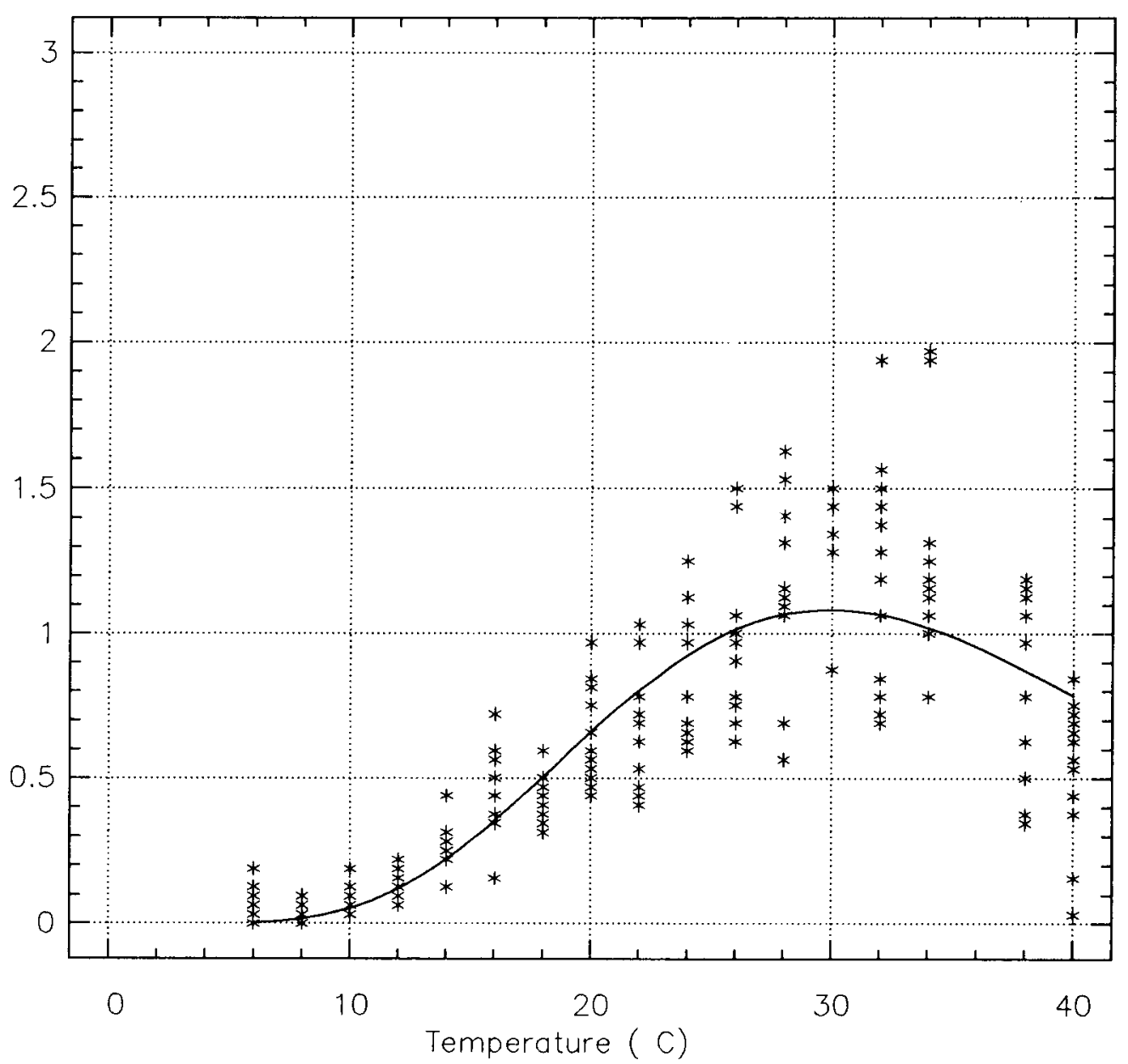

Fig 1. Example of fitted curve by modified gamma model (F2 inbred). 
$28-30^{\circ} \mathrm{C}$ (see fig 1 for the elongation rate of line F2).

\section{Research of genetic variation using linear regression}

Test of parallelism of the regression lines shows a significantly higher slope for W64A and W64A $x$ F546. The other lines behave in a similar manner to $\mathrm{F} 2 \times \mathrm{W} 117$ and exotic populations.

Another important parameter to compare is the base temperature (BT). The $B T$ was defined as the value of temperature when predicted elongation rate was equal to zero. But, because of the dubiousness of the value, none of the statistical tests used was precise enough to distinguish all the $B T$. According to the confidence intervals, EP1 is the only genotype with a $B T$ significantly higher than the others (fig 2).

It was therefore not possible to prove the existence of genetic variation for sensitivity to temperature. As a matter of fact, when 2 genotypes differ only by slope, they differ in vigour but ratios between elongation rates at 2 given temperatures are equal for both of them (fig 3 ). In this case, a genotype with a higher slope is more suitable for breeding because it is not more sensitive but grows faster.

\section{Determination of genetic variation using non-linear methods}

The fitted curves obtained for most of the genotypes are presented in figure 4 . The inbred lines

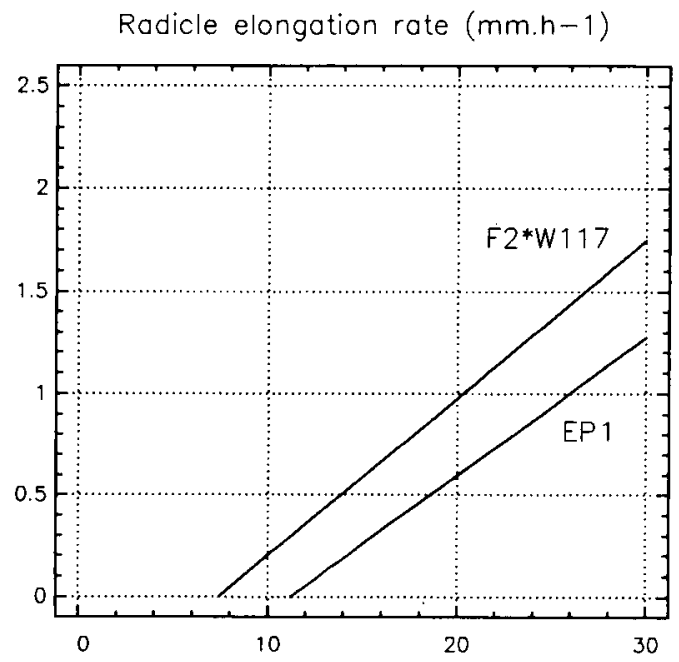

Fig 2. Comparison between regression lines. EP1 and $F 2 x$ W117 differ in sensitivity (different slopes with different BT) but F2 $\times$ W117 is always more vigorous. are all different except for the $c$ parameter. Even if W64A shows a higher value, there is no statistical difference between the 5 coefficients and a common estimate $(0.203)$ was thus calculated. Except for W64A, the optimum temperature (b) is $29.5^{\circ} \mathrm{C}$ (common value estimated for the 4 other lines) and the growth rates at $0{ }^{\circ} \mathrm{C}(d)$ are equal (0-0.04 mm/h) (table II).

Concerning hybrids, W64A $\times$ F546 is completely different from $\mathrm{F} 2 \times \mathrm{W} 117$ and $\mathrm{W} 117 \times \mathrm{F}^{2}$. It had the same characteristics as its parent W64A: an optimum which is low, a growth rate at $0^{\circ} \mathrm{C}$ and a $c$ parameter which are high.

The populations are also different except for growth at $0{ }^{\circ} \mathrm{C}$. A common estimation can be found $(89.9 \mu / \mathrm{h})$ in spite of the lower value shown by Pop 86. Pool 4 and Sexa have the same optimum at $29^{\circ} \mathrm{C}$. It occurs at a lower temperature $\left(26.4^{\circ} \mathrm{C}\right)$ for Pop 86.

\section{Behaviour at low temperature}

Equality to zero of mean elongation rate was tested by a Student test. Radicles of most of the genotypes grow longer at $6^{\circ} \mathrm{C}$ (table III). These results do not agree with the thresholds usually quoted for heterotrophic growth (Barloy, 1984). This is probably due to the feature studied: elongation is not equivalent to growth measured by an increase in dry matter weight. Elongation probably results here in passive absorption of water. According to Blacklow (1972b), this phenomenon is not inhibited by low temperature.

It is also possible to use the non linear method. Equality to zero of the $d$ parameter was de-

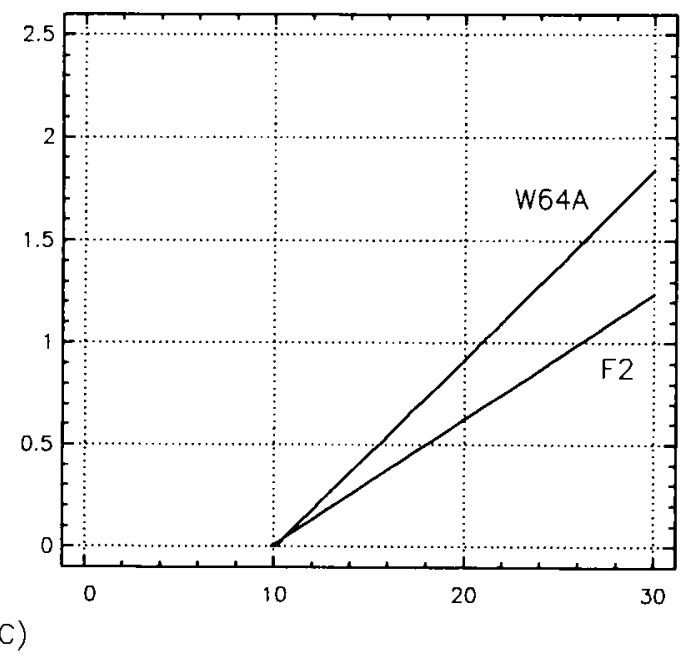

Fig 3. Comparison between regression lines. F2 and W64A differ oniy in vigour. 
Rodicle elongation rate $(\mathrm{mm} . \mathrm{h}-1)$

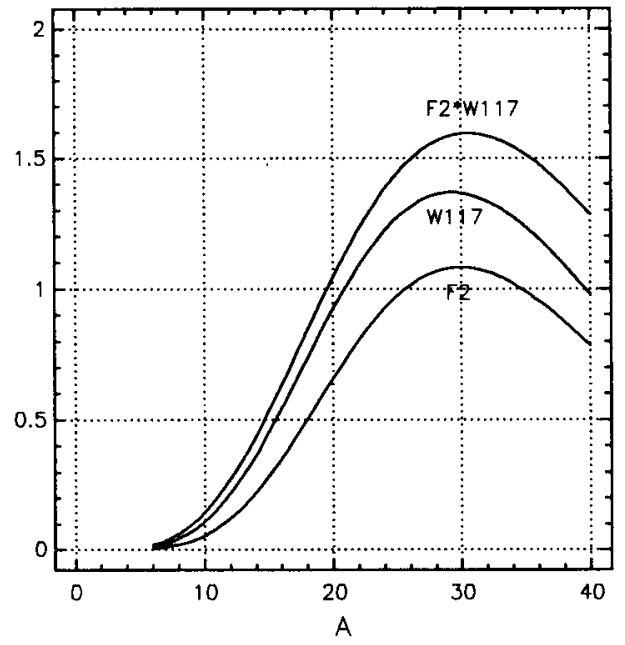

Comparison between hybrid and parental inbreds.

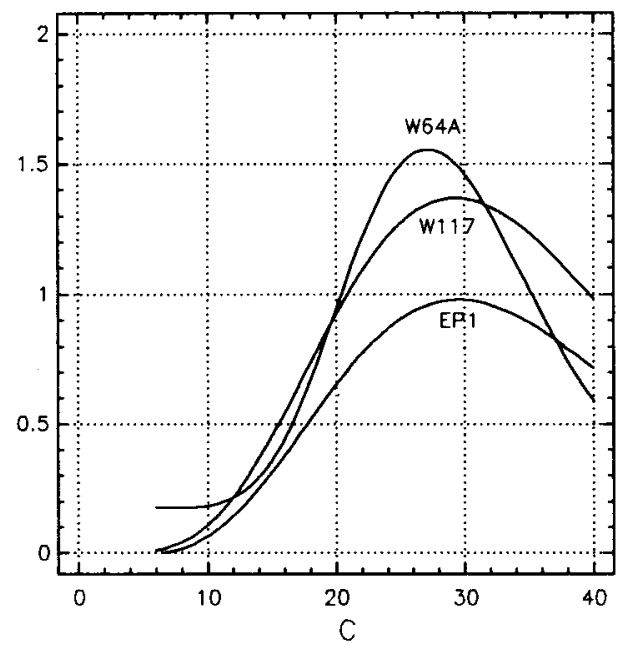

Comparison among inbreds.

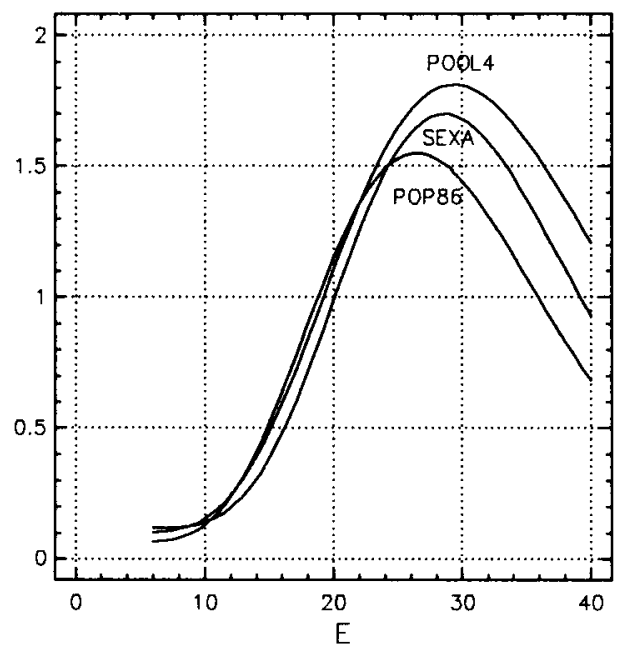

Comparison among exotic populations.

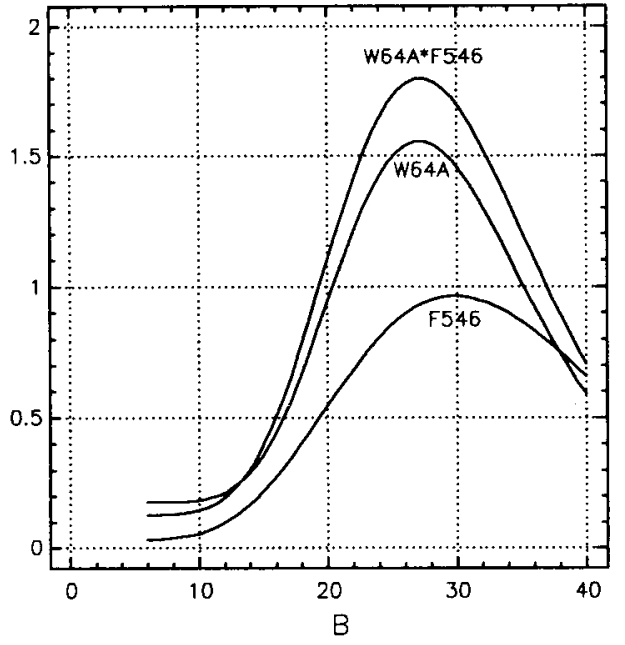

Comparison between hybrid and parentol inbreds.

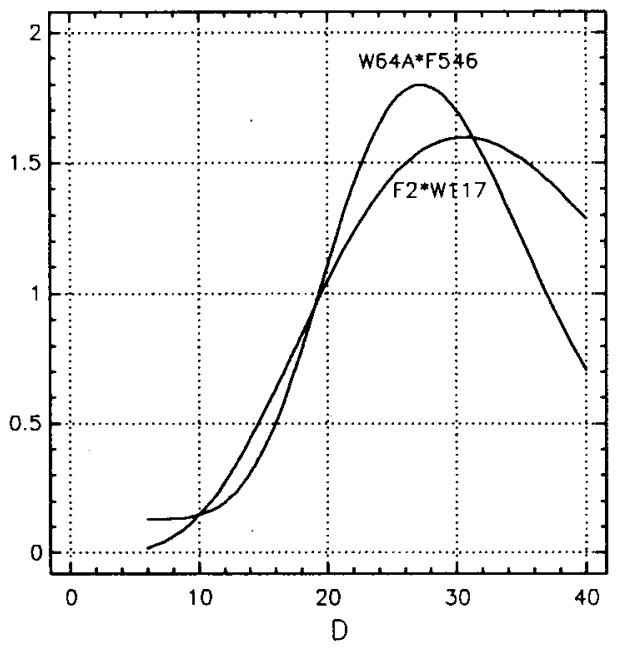

Comparison amang hybrids.

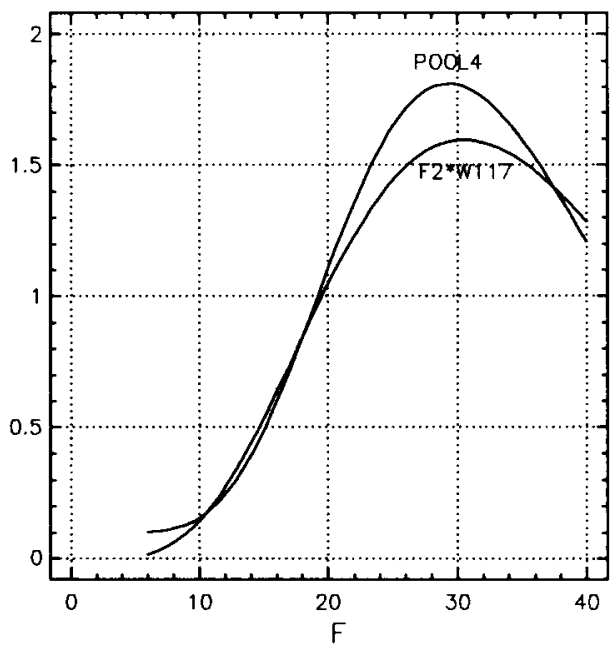

Comparison between exotic population and adapted hybrid.

Fig 4. Comparison of effects of temperature on radicle elongation rate of several genotypes. 
Table II. Parameter estimation in modified gamma model.

\begin{tabular}{|c|c|c|c|c|}
\hline \multirow{2}{*}{ Genotype } & \multicolumn{4}{|c|}{ Estimated value of coefficients } \\
\hline & $a$ & $b$ & $c$ & $d$ \\
\hline EP1 & $5.84 \cdot 10^{-7}$ & 29.49 & 0.204 & -0.0141 \\
\hline F2 & $8.38 \cdot 10^{-9}$ & 30.06 & 0.258 & 0.0403 \\
\hline W117 & $1.47 \cdot 10^{-7}$ & 29.18 & 0.232 & 0.0398 \\
\hline $\mathrm{F} 2 \times \mathrm{W} 117$ (LS) & $1.34 \cdot 10^{-6}$ & 30.28 & 0.192 & 0.0245 \\
\hline $\mathrm{F} 2 \times \mathrm{W} 117$ (SS) & $4.12 \cdot 10^{-7}$ & 30.19 & 0.209 & 0.0226 \\
\hline $\mathrm{W}_{1} 17 \times \mathrm{F} 2$ (LS) & $1.28 \cdot 10^{-9}$ & 27.69 & 0.323 & 0.0619 \\
\hline $\mathrm{W}_{1} 17 \times \mathrm{F} 2$ (SS) & $1.53 \cdot 10^{-10}$ & 28.30 & 0.345 & 0.0793 \\
\hline F546 & $1.69 \cdot 10^{-9}$ & 29.87 & 0.281 & 0.0306 \\
\hline W64 A & $1.72 \cdot 10^{-14}$ & 27.12 & 0.513 & 0.1755 \\
\hline W64A x F546 & $5.36 \cdot 10^{-13}$ & 27.20 & 0.459 & 0.1286 \\
\hline Pool 4 & $6.12 \cdot 10^{-9}$ & 29.35 & 0.279 & 0.1005 \\
\hline Sexa & $2.65 \cdot 10^{-11}$ & 28.58 & 0.369 & 0.1202 \\
\hline Pop 86 & $2.86 \cdot 10^{-9}$ & 26.41 & 0.334 & 0.0636 \\
\hline
\end{tabular}

LS : large size; SS : small size.

termined. This test gives a good idea of the behaviour at low temperature due to the flatness of the curves between $6-10^{\circ} \mathrm{C}$.

Equality is accepted for EP1 and F2 $\times \mathrm{W}_{117}$. The interest of Pool 4 and Sexa against POP 86 is confirmed (table IV).

\section{Comparison between hybrids and parental inbred lines}

The linear regression coefficients are equal for $\mathrm{F} 2 \times \mathrm{W} 117, \mathrm{~W} 117 \times \mathrm{F} 2$ and $\mathrm{W} 117$, as for W64A $x$ F546 and W64A. On the other hand, non-linear

Table III. Test of equality to zero of mean radicle growth rates for the low temperatures.

\begin{tabular}{|c|c|c|c|c|c|c|}
\hline Genotype & $\begin{array}{l}\text { Mean growth } \\
\text { rate at } 6^{\circ} \mathrm{C}\end{array}$ & $\begin{array}{c}\text { Equality to } \\
\text { zero } \\
x \text {-error }=5 \%\end{array}$ & $\begin{array}{l}\text { Mean growth } \\
\text { rate at } 8^{\circ} \mathrm{C}\end{array}$ & $\begin{array}{l}\text { Equality to } \\
\text { zero } \\
x \text {-error }=5 \%\end{array}$ & $\begin{array}{l}\text { Mean growth } \\
\text { rate at } 10^{\circ} \mathrm{C}\end{array}$ & $\begin{array}{l}\text { Equality to } \\
\text { zero } \\
x \text {-error }=5 \%\end{array}$ \\
\hline EP1 & -0.0130 & Yes & 0.0341 & Yes & 0.0750 & No \\
\hline $\mathrm{F} 2$ & 0.0521 & No & 0.0339 & Yes & 0.0599 & No \\
\hline$W 117$ & 0.0573 & No & 0.0859 & No & 0.0964 & No \\
\hline $\mathrm{F} 2 \times \mathrm{W} 117$ (LS) & 0.0277 & No & 0.0651 & No & 0.1719 & No \\
\hline $\mathrm{F} 2 \times \mathrm{W} 117$ (SS) & 0.0286 & No & 0.0495 & No & 0.1307 & No \\
\hline W117 x F2 (LS) & 0.0156 & Yes & 0.0573 & No & 0.1797 & No \\
\hline$W_{117} \times F_{2}(\mathrm{SS})$ & 0.0625 & No & 0.0982 & No & 0.1432 & No \\
\hline F546 & 0.0156 & Yes & 0.0286 & Yes & 0.0547 & No \\
\hline W64A & 0.0964 & No & 0.1120 & No & 0.1901 & No \\
\hline W64A x F546 & 0.0677 & No & 0.1328 & No & 0.1875 & No \\
\hline Pool 4 & 0.0547 & No & 0.0990 & No & 0.1310 & No \\
\hline Sexa & 0.0573 & No & 0.2072 & No & 0.1615 & No \\
\hline Pop 86 & 0.0208 & Yes & 0.0911 & No & 0.1719 & No \\
\hline
\end{tabular}

LS : large size; SS : small size. 
Table IV. Test of equality to zero of the D parameter of modified gamma model.

\begin{tabular}{lll}
\hline Genotype & $\begin{array}{l}\text { Equality to zero of } \\
\text { the D parameter }\end{array}$ & $\begin{array}{l}\text { X-error } \\
\text { (\%) }\end{array}$ \\
\hline EP1 & Yes & \\
F2 & No & 0.001 \\
W117 & No & 5 \\
F2 $\times$ W117 (LS) & Yes & \\
F2 $\times$ W117 (SS) & Yes & 0.5 \\
W117 F2 (LS) & No & 5 \\
W117 $F 2$ (SS) & No & 0.001 \\
F546 & No & 0.001 \\
W64A & No & 0.005 \\
W64A F546 & No & 0.001 \\
Pool 4 & No & 5 \\
Sexa & No & \\
Pop 86 & & \\
\end{tabular}

LS : large size; SS : small size.

comparison shows that hybrids are different from all their parental inbreds. Nevertheless, F2, W117 and their hybrids differ only in the scale parameters, possibly in vigour effects. It is also interesting to observe the common features of W64A and its hybrid W64A x F546 which prove the possibility of inheritance of juvenile growth characteristics.

\section{Influence of crossing method and seed size}

The linear method showed no difference between crossing method or seed size of the hybrid between F2 and W117. On the other hand, the non-linear method allows the 2 crossing methods to be distinguished. This result confirmed the general opinion about seed influence on juvenile characteristics.

\section{CONCLUSION}

The investigation shows the existence of genetic variation for maize seedling growth at different temperatures. Genotypes are characterized by different elongation rates at low temperature, different optimum temperatures and different sensitivities to temperature. Sometimes there is only a difference in vigour which is possibly an expression of heterosis.

It should be noted that this study does not allow seed reserve effects to be separated from genotype influence. It would be interesting to study grain filling in order to examine this point.

In other respects, observations have not been based on dry matter weight measures but on elongation. A study of dry matter accumulation during the seedling stages of development would be necessary to characterize genotypes according to another criterium more closely associated with early vigour tests used by breeders.

\section{ACKNOWLEDGMENTS}

The authors thank A Marin-Laflèche and S Huet for their introduction to and assistance with CS-NL.

\section{REFERENCES}

Barloy J (1984) Phase germination, levée et implantation. In: Physiologie du Maïs. INRA, 13-48

Blacklow WM (1972a) Influence of temperature on germination and elongation of the radicle and shoot of corn (Zea mays L). Crop Sci 12, 647-650

Blacklow WM (1972b) Mathematical description of the influence of temperature and seed quality on imbibition by seed of corn (Zea mays L). Crop Sci 12, 643-646

Bouvier A, Gelis F, Huet S, Messean A, Neveu P (1985) CS-NL. Laboratoire de Biométrie, INRACNRZ, Jouy-en-Josas, pp 180

Clarkson DT, Gerloff GC (1979) The Effects of Temperature on Root Growth and Mineral Nutrition of 
Young Maize Plants. Ann Rep 1978, Letcombe Lab, Wantage, 52-54

Grawford RMM, Huxter TJ (1977) Root growth and carbohydrate metabolism at low temperatures. $J$ Exp Bot 28(105), 917-925

Giauffret $C$ (1989) Croissance hétérotrophe et température chez le maïs : étude de la variabilité génétique. Mémoire DEA, INA Paris-Grignon

Lebreton JD, Millier (1982) Modèles Dynamiques Déterministes en Biologie. Masson, pp 207
Lehenbauer PA (1914) Growth of maize in relation to temperature. Physiol Res 1 (5), 247-288

McAdam JH, Hayes P (1978) The effect of temperature on the germination of seven cultivars of Zea mays L. Rec Agric Res 26, 55-61

Tollenaar M, Daynard TB, Hunter RB (1979) Effect of temperature on rate of leaf appearance and flowering date in maize. Crop Sci 19, 363-366

Varlet-Grancher C (1982) Analyse du rendement de la conversion de l'énergie solaire par un couvert végétal. Thèse No 2593, Université de Paris-Sud, Orsay 